\title{
Behavioral tagging in infant rats
}

\author{
Sarah E. Bae and Rick Richardson \\ School of Psychology, UNSW Sydney, New South Wales 2052, Australia
}

\begin{abstract}
Recent studies have shown that exposure to a novel environment may stabilize the persistence of weak memories, a phenomenon often attributed to a process referred to as "behavioral tagging." While this phenomenon has been repeatedly demonstrated in adult animals, no studies to date have examined whether it occurs in infant animals, which is surprising given that infants exhibit an impaired ability to form long-term memories (LTMs). In the present study, infant (i.e., postnatal day (P) 17) rats were placed in a context and repeatedly shocked. Infant rats given brief open field exposure $1 \mathrm{~h}$, but not $2 \mathrm{~h}$, prior to conditioning exhibited enhanced retention when tested $1 \mathrm{~d}$ later (Experiments 1 and 2), but comparable retention when tested shortly after training (Experiment 2). Thus, exploration of an open field facilitates subsequent context fear memories by enhancing the persistence of the memory rather than strengthening the context-shock association at encoding. While exploration of an open field did not lead to better memory when animals were tested $3 \mathrm{~d}$ later (Experiment 3 ), a brief pretest shock led to a more pronounced reinstatement effect in rats exposed to the open field $1 \mathrm{~h}$ before conditioning (Experiment 4 ). Finally, unlike what has been reported in adults, Experiments 5 and 6 suggest that familiarization of the open field before subsequent exposure does not abolish the behavioral tagging effect in infants. Overall, while these findings suggest that similar behavioral tagging mechanisms to those reported in adults might be involved in the formation of LTMs in infant rats, they also suggest that there may be developmental differences in the retention of familiarization experiences.
\end{abstract}

[Supplemental material is available for this article.]

Emerging evidence has demonstrated that unrelated novelty or surprise may stabilize the persistence or strength of weak memories (Moncada and Viola 2007; Ballarini et al. 2009; Moncada et al. 2011; de Carvalho Myskiw et al. 2013). For example, some studies have shown that exposing adult rats to a novel context $1 \mathrm{~h}$ before spatial learning, using parameters that result in a weak memory trace, extends the persistence of that memory. This remarkable phenomenon, referred to as behavioral tagging, has been suggested to be a behavioral analog of synaptic tag and capture (STC) processes. According to the STC theory, transient LTP induced by weakly encoded memories can be stabilized into a longer lasting form by events that occur either soon before or after the event due to the increased availability of plasticity-related proteins (PRPs; Frey and Morris 1997). The behavioral tagging framework often utilizes exploration of a novel environment as a means of increasing the production of proteins that are captured by the synaptic tags set on the weakly stimulated pathway. Without the novel experience, animals experiencing an event that would lead to a weakly encoded memory have insufficient levels of plasticity-related proteins resulting in the memory not being stabilized and converted to long-term memory (LTM).

In the first demonstration of behavioral tagging, Moncada and Viola (2007) not only demonstrated that exploration of a novel open field facilitated the formation of LTM for a subsequent conditioning experience but also that this effect was time-dependent. Specifically, LTM for the weak conditioning experience was only formed when novel exploration occurred $1 \mathrm{~h}$, but not $2 \mathrm{~h}$, before or after conditioning. They also found that blocking the synthesis of PRPs through prior familiarization to the environment, infusion of a dopamine D1/D5 antagonist, or infusion of a protein synthesis inhibitor abolished the facilitating effect of exploration on LTM formation. This finding has since been replicated in several studies with various tasks (Ballarini et al. 2009; Moncada et al. 2011; de Carvalho Myskiw et al. 2013). In one study the behavioral tagging

\section{Corresponding author: s.bae@unsw.edu.au}

Article is online at http://www.learnmem.org/cgi/doi/10.1101//m.047605.118. effect was demonstrated in conditioned taste aversion, contextual conditioning, and spatial object recognition tasks (Ballarini et al. 2009). Importantly, in that study, the type of novel experience was critical in determining whether a facilitation of LTM formation occurred or not. Specifically, the formation of LTM for a hippocampus-dependent task (i.e., contextual conditioning and spatial object recognition) was facilitated by exposure to a novel environment but not a novel taste. The opposite pattern, however, was found for conditioned taste aversion, a task that is dependent on the insular cortex. That is, exposure to a novel taste, but not a novel environment, promoted the formation of LTM for a conditioned taste aversion. Taken together, these findings are consistent with the STC theory which posits that synthesized PRPs must interact both temporally and spatially with the neuronal population "tagged" during the weak conditioning experience in order for that learning experience to be converted to LTM.

While there have been several studies documenting behavioral tagging, all have used adult rodents. These studies demonstrating that "weak" experiences normally sufficient only to support short term memory (STM) can be transformed into LTM by novelty exposure in adult rodents have provided unique insights into the processes underlying memory. It is unclear, however, whether these findings can be translated to the immature rat. This is of interest given that, in contrast to adult animals which have been shown to be capable of retaining memories for context-shock associations for at least 16 mo (Gale et al. 2004), infants are markedly poorer in retaining such memories (e.g., Rudy 1993; Rudy and Morledge 1994; Weber et al. 2006). This impairment appears to be attributable to poor LTM for that experience rather than impaired learning as infant animals exhibit high levels of context

\footnotetext{
(C) 2018 Bae and Richardson This article is distributed exclusively by Cold Spring Harbor Laboratory Press for the first 12 months after the full-issue publication date (see http://learnmem.cshlp.org/site/misc/terms.xhtml). After 12 months, it is available under a Creative Commons License (AttributionNonCommercial 4.0 International), as described at http://creativecommons. org/licenses/by-nc/4.0/.
} 
fear immediately after conditioning but poor retention of this learning experience $24 \mathrm{~h}$ later (Rudy 1993). Thus, the behavioral tagging framework may allow for a novel means to facilitate the persistence of memories in the infant.

From the perspective of the STC theory, a possible factor contributing to the impaired formation of LTM in infant rats involves a limited or insufficient supply of PRPs. Consistent with this notion, Kabitzke et al. (2011) demonstrated that infant rats (postnatal day [P] 14), who exhibited impaired contextual fear conditioning, also did not express increased levels of phosphorylated cAMP-response element binding protein (pCREB), a critical transcription factor involved in the expression of new proteins associated with LTM formation. This was in contrast to juvenile rats (P26) that demonstrated a robust context fear memory as well as increased levels of hippocampal pCREB following learning. This difference is unlikely to be due to an impairment in producing the protein as CREB activation has been demonstrated in the hippocampus in rats as young as P10 (Bender et al. 2001). Taken together, these findings suggest that increasing the supply of PRPs through novel open field exposure around the time of learning may facilitate the formation of long-term context memories in the infant rat.

Considering that memories formed early in life are vulnerable to being forgotten (i.e., a phenomenon referred to as "infantile amnesia"; Campbell and Spear 1972; Josselyn and Frankland 2012; Callaghan et al. 2014; Madsen and Kim 2016; Alberini and Travaglia 2017), it is possible that brief exposure to a novel environment may provide the necessary plasticity-related proteins to support their retention. Therefore, in this study we examined whether exploration of a novel open field enhances context fear memories in infant rats. Together, the results provide evidence for a timedependent behavioral tagging process in infant rats. Further, we demonstrate that this behavioral tagging effect occurs even when infant rats are exposed to a familiar environment (unlike what is observed in adults), suggesting that there may be developmental differences in the retention of familiarization experiences.

\section{Results}

Experiments 1 and 2: brief open field exposure $1 \mathrm{~h}$, but not $2 \mathrm{~h}$, prior to subsequent conditioning facilitates the retention of long-term context fear memories

According to behavioral tagging models, the effect of open field exposure on LTM formation is time-dependent. Specifically, any PRPs produced by open field exploration should decay over time, with most studies demonstrating no evidence for a behavioral tagging effect if open field exposure occurs $2 \mathrm{~h}$ before conditioning (e.g., Moncada and Viola 2007; Moncada et al. 2011). Experiment 1 aimed to investigate whether behavioral tagging occurs in the infant rat and whether it is also time-dependent. Infant rats either remained in their home cage (group CTRL) or were given a single 5 -min exposure to an open field 1 or $2 \mathrm{~h}$ before context fear conditioning (groups OF1 and OF2, respectively). Rats were tested back in the conditioned context and levels of freezing were measured the following day.

A one-way ANOVA revealed significant group differences $\left(F_{(2,35)}=4.64, P=0.02\right.$; Fig. 1). Post-hoc comparisons, with the SNK test, showed that brief open field exposure $1 \mathrm{~h}$ prior to context conditioning resulted in increased levels of context fear at test compared to the other two groups $(P<0.05)$; no differences in freezing were found between rats exposed to the open field $2 \mathrm{~h}$ before conditioning and the control group $(P=0.96)$. Thus, exploration of a novel environment $1 \mathrm{~h}$, but not $2 \mathrm{~h}$, prior to conditioning facilitated long-term retention of context fear in the infant rat.

Based on behavioral tagging models, PRPs produced by spatial exploration should facilitate the formation of long- but not short-

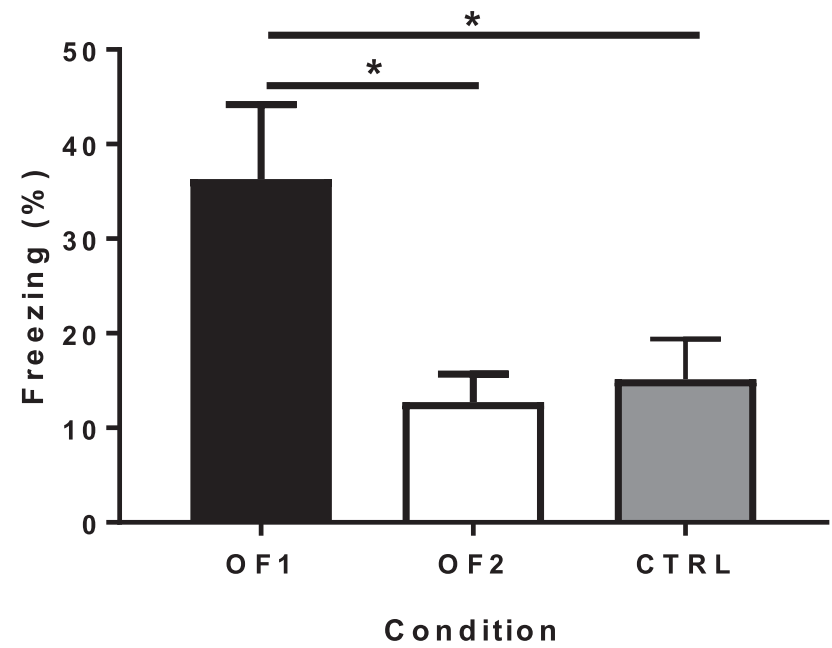

Figure 1. All experiments began when rats were $17 \mathrm{~d}$ of age, with the day of birth being designated as day 0 . Mean $( \pm S E M)$ levels of freezing at test for groups exposed to a novel open field $1 \mathrm{~h}(\mathrm{OF} 1 ; n=14)$ or $2 \mathrm{~h}$ (OF2; $n=11$ ) before conditioning and control rats that were conditioned only (CTRL; $n=13)$. ( $\left.{ }^{*}\right)$ indicates a significant difference $(P<0.05)$.

term memories by acting on processes involved in memory stabilization following encoding (Dunsmoor et al. 2015). Therefore, the aims of Experiment 2 were twofold. First, we aimed to replicate the novel findings from Experiment 1 demonstrating that open field exposure $1 \mathrm{~h}$, but not $2 \mathrm{~h}$, before conditioning facilitates LTM formation in infant rats. Second, we aimed to investigate whether open field exposure facilitates LTM formation by facilitating the persistence of the memory rather than the strength of the context-shock association during encoding. In this experiment, rats were exposed to an open field either 1 or $2 \mathrm{~h}$ before conditioning, and then tested either after a short (1-min) or long (1-d) retention interval. Performance at the 1-min interval will reveal whether open field exposure facilitates the retention of long-term context fear memories via its influence on processes involved in memory encoding or stabilization, while performance at the 1-d interval will provide a replication of the results in Experiment 1 .

Freezing levels at test are shown in Figure 2. A $2 \times 2$ ANOVA revealed a significant open field condition $\mathrm{x}$ test interval interaction $\left(F_{(1,44)}=4.56, P=0.038\right)$, with follow-up independent samples $t$-tests showing that levels of freezing between rats exposed to the open field 1 and $2 \mathrm{~h}$ before conditioning differed at the long-term test $\left(t_{22}=2.76, P=0.011,95 \% \mathrm{CI}[5.31,37.19]\right)$ but not at the shortterm test $\left(t_{22}=0.41, P=0.68,95 \%\right.$ CI $\left.[-21.71,14.51]\right)$. The main effects of open field condition $\left(F_{(1,44)}=2.30, P=0.13\right)$ and test interval $(F<1.0)$ were not significant. These results suggest that exploration of a novel open field facilitates subsequent context fear memories in infant rats by enhancing the persistence of the memory rather than strengthening the context-shock association at encoding. Further, consistent with the results of Experiment 1 and past work in adults, the results demonstrate that this facilitation of long-term context memory in infant rats is time-dependent, supporting the notion of a behavioral tagging process in infancy.

\section{Experiments 3 and 4: brief open field exposure $1 \mathrm{~h}$ prior to subsequent contextual conditioning results in a more durable memory trace}

While the results of Experiments 1 and 2 show that brief open field exposure facilitates the long-term retention of context fear memories in infant rats, test occurred only $1 \mathrm{~d}$ after conditioning. Given that infant rats typically exhibit rapid forgetting even after a 


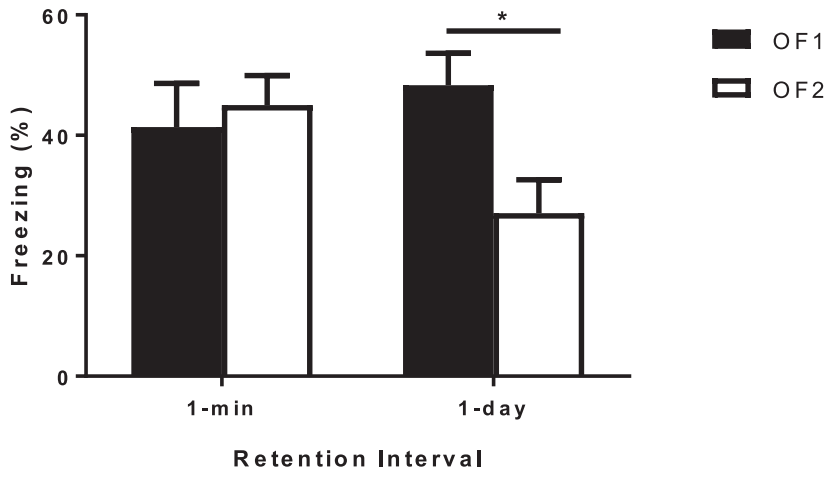

Figure 2. Mean $( \pm$ SEM) levels of freezing at test for rats exposed to a novel open field $1 \mathrm{~h}$ before conditioning and tested after 1 min (OF1-1 min; $n=12$ ) or $1 \mathrm{~d}(\mathrm{OF} 1-1 \mathrm{~d} ; n=12)$, and rats exposed to the open field $2 \mathrm{~h}$ before conditioning and tested after $1 \mathrm{~min}(\mathrm{OF} 2-1 \mathrm{~min} ; n=12)$ or $1 \mathrm{~d}(\mathrm{OF} 2-1 \mathrm{~d} ; n=12)$. ( $\left.{ }^{*}\right)$ indicates a significant difference $(P<0.05)$.

LTM trace has been formed (i.e., infantile amnesia), in the next two experiments we examined whether open field exposure soon before conditioning results in a memory that persists longer than $1 \mathrm{~d}$ in the infant rat. In Experiment 3 rats were exposed to an open field either 1 or $2 \mathrm{~h}$ before conditioning and then tested either 1 or $3 \mathrm{~d}$ after conditioning.

Analysis of the test data yielded significant main effects of open field condition $\left(F_{(1,42)}=7.41, P=0.009\right)$ and test interval $\left(F_{(1,42)}=4.25, P=0.045\right)$; the interaction was not significant $\left(F_{(1,42)}=\right.$ $2.58, P=0.11$; see Fig. 3$)$. Despite the interaction not being significant, exploratory post-hoc analyses were performed and revealed that rats exposed to the open field 1 or $2 \mathrm{~h}$ before conditioning differed in their levels of freezing when tested at the $1 \mathrm{~d}$ interval $\left(t_{15.202}=2.70, P=0.016,95 \%\right.$ CI $\left.[4.88,40.95]\right)$ but not the $3 \mathrm{~d}$ interval $\left(t_{20}=0.97, P=0.34,95 \%\right.$ CI $\left.[-6.73,18.55]\right)$. These results replicate those of the first two experiments at the 1-d interval, and suggest that the facilitating effects of exposure to a novel open field shortly prior to conditioning has a relatively restricted effect in regards to how long the memory is retained (i.e., no effect seen after $3 \mathrm{~d}$ ).

Past work has shown that infant rats can retrieve apparently forgotten memories if a reminder US is given before test (e.g., $\mathrm{Li}$ et al. 2014; Spear and Parsons 1976). Therefore, to further explore the apparent short-lived effect of open field exposure on the retention of memories in the infant rat, in Experiment 4 we administered a weak reminder foot shock US, in a different context, the day prior to test. Rats were exposed to the open field either 1 or $2 \mathrm{~h}$ before conditioning, and then tested $3 \mathrm{~d}$ later. All animals received the weak reminder shock the day before test. A third "reminder only" group received the weak foot shock the day before test, but had not been given the initial context training (this group is a control for the possibility of generalized context fear from the "reminder" shock alone).

Freezing levels at test are shown in Figure 4. A one-way ANOVA revealed significant group differences $\left(F_{(2,33)}=39.27, P<\right.$ 0.001). Post-hoc comparisons, with the SNK test, showed that rats exposed to the open field $1 \mathrm{~h}$ before conditioning had significantly higher levels of freezing at test than the other two groups $(P<0.05)$; the rats exposed to the open field $2 \mathrm{~h}$ before conditioning exhibited higher levels of freezing than the reminder only group $(P<0.05)$. Thus, although both trained groups exhibited a reinstatement effect, relative to a nontrained group merely given the "reminder" shock prior to test, those animals exposed to the open field $1 \mathrm{~h}$ before conditioning exhibited a significantly greater reinstatement effect than those exposed to the open field $2 \mathrm{~h}$ before conditioning. These findings suggest that open field exposure $1 \mathrm{~h}$ before conditioning results in a more robust memory trace, leading to greater levels of reinstatement relative to rats given the same exploration experience $2 \mathrm{~h}$ before conditioning. This suggests that the lower levels of freezing observed in Experiment 3 at the $3 \mathrm{~d}$ test in those animals exposed to the open field $1 \mathrm{~h}$ before conditioning are due to difficulties retrieving the context-shock memory rather than its loss from storage.

\section{Experiments 5 and 6: familiarizing infant rats to the open field does not abolish the behavioral tagging effect}

In Experiment 5, we examined whether familiarization of the open field would affect the facilitating effect of subsequent open field exposure on the long-term retention of context fear. Past research has shown that familiarizing adults to the open field blocks its promoting effect on LTM (Ballarini et al. 2009). Further, consistent with behavioral tagging principles, this familiarization experience was shown to block the typical increase in hippocampal phosphorylated CREB (pCREB) observed in rats $1 \mathrm{~h}$ after open field exploration (Moncada and Viola 2006). Given these results, in this experiment two groups of infant rats were exposed to an open field $1 \mathrm{~h}$ before conditioning. One of these groups had been familiarized to the open field (for 20-min) the day before while the other had remained in their home cage on that day. A third group of infants, as a control group, received no familiarization exposure to the open field and were exposed to it $2 \mathrm{~h}$ before conditioning.

A one-way ANOVA yielded a significant group difference $\left(F_{(2,36)}=3.67, P=0.035\right.$; see Fig. 5$)$, with pairwise comparisons (SNK test) showing that familiarized and nonfamiliarized rats exposed to the open field $1 \mathrm{~h}$ before conditioning froze significantly more than rats exposed to the open field $2 \mathrm{~h}$ before conditioning $(P<0.05$ and $P=0.05$, respectively). These results replicate those in Experiments 1 to 4 showing that open field exposure $1 \mathrm{~h}$, but not $2 \mathrm{~h}$, before conditioning facilitates retention of a context fear memory when infants are tested $1 \mathrm{~d}$ later. Interestingly, contrary to past work in adults (Moncada and Viola 2007; Ballarini et al. 2009; de Carvalho Myskiw et al. 2013), familiarization to the open field did not appear to affect this behavioral tagging process in the infant rat.

The final experiment in this study investigated whether shortening the interval between familiarization and subsequent open field exposure would reduce the facilitating effect of such exploration on LTM formation. Specifically, the results of the previous

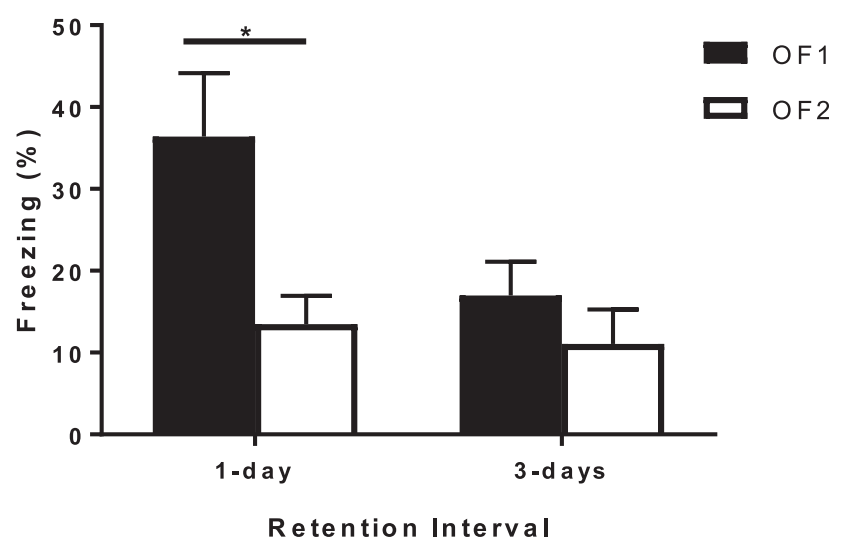

Figure 3. Mean ( \pm SEM) levels of freezing at test for rats exposed to a novel open field $1 \mathrm{~h}$ before conditioning and tested after 1 (OF1-1 d; $n=12)$ or $3 \mathrm{~d}$ (OF1-3d; $n=12)$, and rats exposed to the open field $2 \mathrm{~h}$ before conditioning and tested after 1 (OF2-1 d; $n=11)$ or $3 \mathrm{~d}$ (OF2-3 d; $n=11)$. ( $\left.{ }^{*}\right)$ indicates a significant difference $(P<0.05)$. 


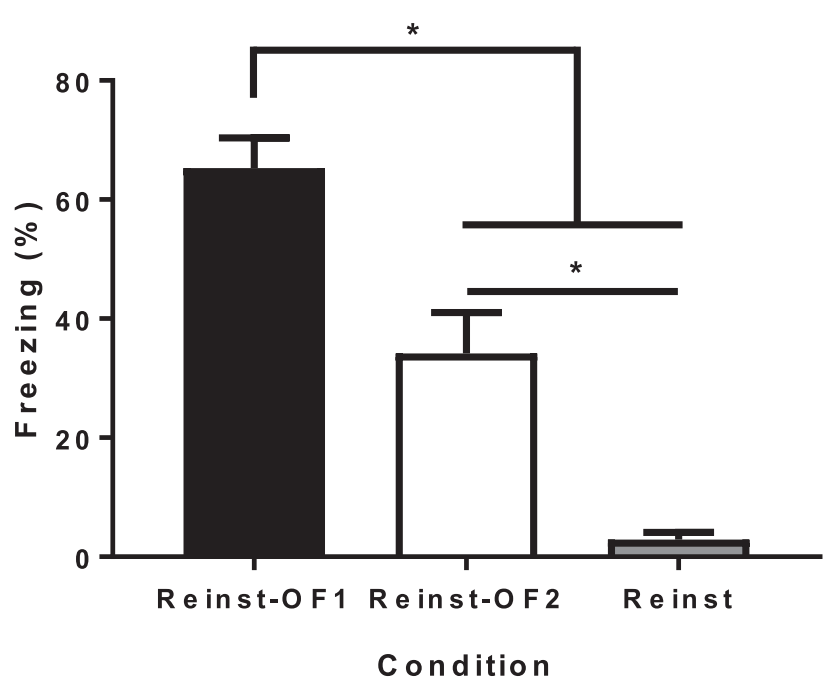

Figure 4. Mean ( \pm SEM) levels of freezing at test for rats exposed to a novel open field 1 (Reinst-OF1; $n=12$ ) or $2 \mathrm{~h}$ (Reinst-OF2; $n=12$ ) before conditioning and given a reinstating foot shock the day before test and rats given the reinstating foot shock only (Reinst; $n=12$ ). ( $\left.{ }^{*}\right)$ indicates a significant difference $(P<0.05)$.

experiment were in contrast to what has been reported in adult animals, given that familiarization to the open field did not appear to have any effect in infants. However, perhaps this was because infants do not retain the familiarization experience for $24 \mathrm{~h}$ (i.e., they have infantile amnesia for this experience). Therefore, in this experiment, two groups of infant rats that were exposed to an open field $1 \mathrm{~h}$ before conditioning were previously familiarized to that environment, one 24 -h earlier and the other 2 -h beforehand. Further, the duration of familiarization was increased to 30-min as that was the duration used in the adult studies demonstrating that familiarizing animals to the open field reduced the behavioral tagging effect (Moncada and Viola 2007; Ballarini et al. 2009; de Carvalho Myskiw et al. 2013). Similar to Experiment 5 , a third, control group of nonfamiliarized rats that were exposed to the open field $2 \mathrm{~h}$ before conditioning were included. All rats were tested the day following conditioning.

Freezing levels at test are shown in Figure 6. A one-way ANOVA revealed significant between-group differences $\left(F_{(2,32)}=\right.$ $3.75 P=0.034)$. Replicating the results of Experiment 5 , post-hoc comparisons (with SNK tests) showed that rats familiarized to the open field $24 \mathrm{~h}$ before a subsequent open field exposure $1 \mathrm{~h}$ before conditioning froze significantly more than control rats exposed to the open field $2 \mathrm{~h}$ before conditioning $(P<0.05)$. A trend toward a significant group difference was observed between the infants familiarized to the open field $2 \mathrm{~h}$ before reexposure and the control rats exposed to the open field $2 \mathrm{~h}$ before conditioning $(P=0.061)$; no differences were found between rats familiarized to the open field 24 or $2 \mathrm{~h}$ before subsequent exposure $(P=0.46)$. These findings demonstrate that familiarization, regardless of whether it occurs soon or long before subsequent exposure, does not block behavioral tagging processes in infant rats. This suggests that there may be developmental differences in the mechanisms involved in the storage and/or retention of long-term representations for familiarization experiences.

\section{Discussion}

A number of recent studies in adult rats have provided evidence for a process known as behavioral tagging. These studies typically uti- lize "weak"' training parameters that are sufficient only to support STM, and demonstrate that these memories can be transformed into LTM by exposure to novelty (e.g., Ballarini et al. 2009). In the present study, we utilized animals that naturally exhibit good STM but poor LTM, that is, infant rats. We demonstrated that open field exposure $1 \mathrm{~h}$, but not $2 \mathrm{~h}$, before conditioning facilitated long but not short term memory formation in infant rats (Experiment 2). Although this context fear memory was apparently forgotten when tested $3 \mathrm{~d}$ after conditioning (Experiment 3), this was due to retrieval difficulties as a brief reminder shock was sufficient to reinstate the memory (Experiment 4). Together, these findings suggest that behavioral tagging processes may also underlie the formation of long-term context fear memories in infant rats. Interestingly, familiarization did not abolish the behavioral tagging effect (Experiments 5 and 6) suggesting that the processes involved in storing or retaining long-term representations for familiarization experiences may differ in the infant compared to the adult.

It is well-established that infant rats are impaired in contextual conditioning relative to older animals (Rudy 1993; Rudy and Morledge 1994). Nonetheless, the levels of freezing in the control group (Experiment 1) was surprisingly low (mean =15\%), given that six shocks were delivered the day prior. These levels of freezing were lower than that observed in infant rats in some of our past studies where context conditioning was assessed in infant animals (e.g., Woodcock and Richardson 2000; Callaghan and Richardson 2011). It is possible that procedural differences could, at least partially, account for these differences in freezing. For example, past studies used smaller chambers and unscrambled footshock whereas the chambers used in the experiments reported here were much larger and use scrambled footshock. Further, it should be noted that the level of performance in the control group in Experiment 1 was comparable to that observed in a pilot study with the same training procedures $(n=9$, mean freezing of $22 \%)$. In addition, the levels of freezing at the 1-d test in the control group (Experiment 1) was similar to the mean level of freezing in rats exposed to the open field 2-h before conditioning (OF2) across the other four experiments (mean $=17 \%$ ); this group acted as a positive control as no benefits from the open field exposure prior to training was expected. While it is possible that open field exposure may

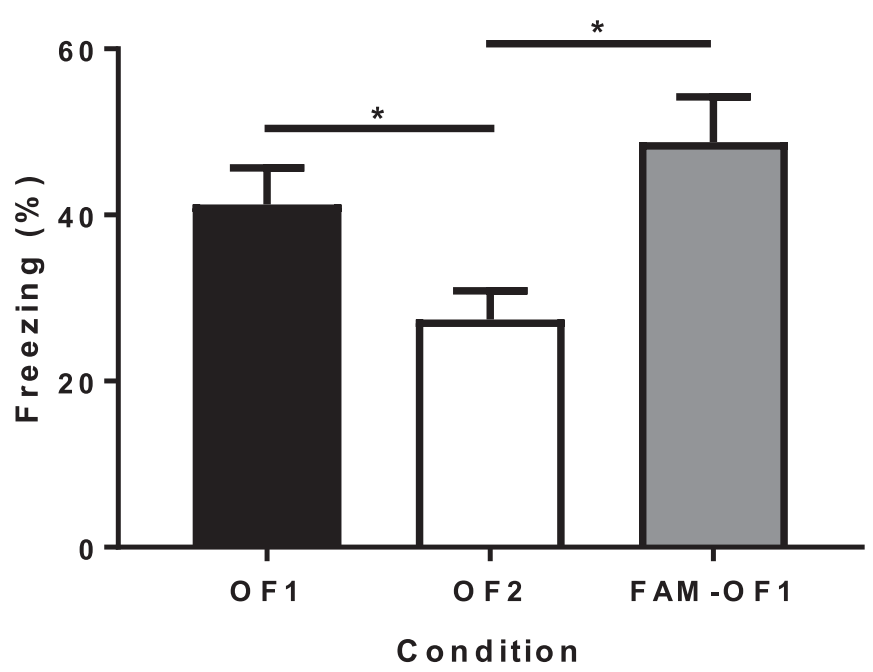

Figure 5. Mean ( \pm SEM) levels of freezing at test for groups exposed to a novel open field 1 (OF1; $n=13$ ) or 2 h (OF2; $n=13$ ) before conditioning, and rats exposed to a familiar open field $1 \mathrm{~h}$ before conditioning (FAM-OF1; $n=13)$. $\left(^{*}\right)$ indicates a significant difference $(P \leq 0.05)$. 


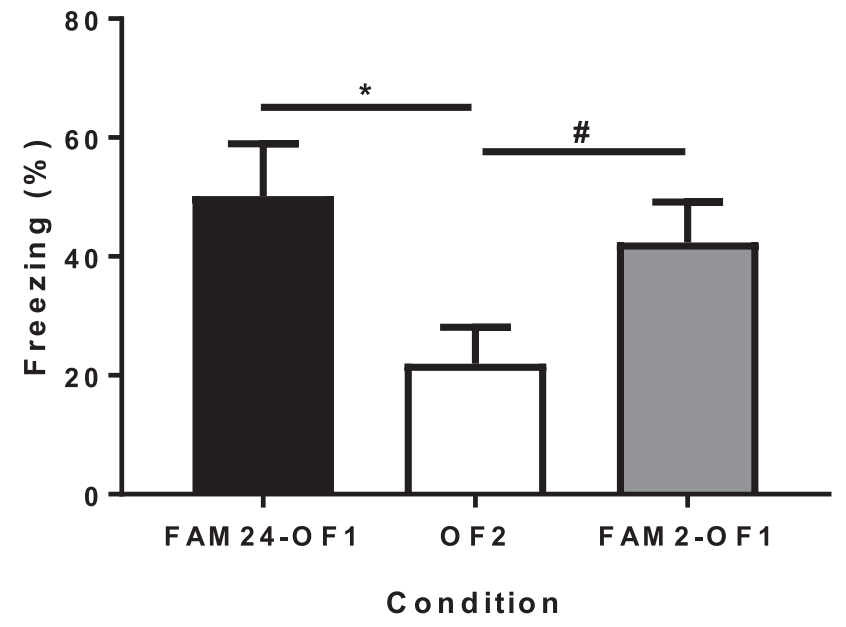

Figure 6. Mean $( \pm S E M)$ levels of freezing at test for groups familiarized to the open field 24 (FAM24-OF1; $n=12$ ) or 2 h (FAM2-OF1; $n=12$ ) before brief open field exposure, and unfamiliarized rats exposed to the open field $2 \mathrm{~h}$ before conditioning (OF2; $n=11$ ). ( $\left.{ }^{*}\right)$ indicates a significant difference $(P<0.05)$. (\#) denotes a trend toward a significant difference $(P=0.061)$.

have continued to have some lasting benefit on training following a 2-h interval, this appears unlikely given the comparable levels of freezing in these groups and the control group that was not exposed to the open field in Experiment 1 as well as in the pilot study. Post-hoc statistical analyses confirmed this description of the data. Specifically, a post-hoc independent samples $t$-test revealed no differences in levels of context fear between the control groups of Experiment 1 and the pilot study $\left(t_{9.214}=0.69, P=0.51,95 \% \mathrm{CI}\right.$ $[-34.11,18.11])$. One-way ANOVAs also revealed no differences between the OF1 groups or the OF2 groups across experiments (Experiments 1, 2, 3, and data from the pilot study for OF1; Experiments 1,2 , and 3 for OF2) $\left(F_{(3,46)}=0.65, P=0.59\right.$ and $F_{(2,32)}=$ $3.18, P=0.06$, respectively). As no differences in levels of context fear were detected between experiments for the control, OF1, and OF2 groups, the data for each of the three conditions were collapsed for subsequent analyses. This yielded a significant effect of group on level of context fear at test $\left(F_{(2,103)}=12.18, P<0.001\right)$. Follow-up independent samples t-tests showed that there was a significant difference between rats exposed to the open field $1 \mathrm{~h}$ before conditioning and rats exposed to the open field 2-h before $\left(t_{80.89}=4.75, P<0.001,95 \%\right.$ CI [12.24, 29.85], $\left.d=1.06\right)$, or control rats that were trained only $\left(t_{69}=3.29, P=0.002,95 \% \mathrm{CI}\right.$ $[8.29,33.82], d=0.79$; means \pm SE were as follows: OF1 $=39.23 \pm$ 3.62, $n=50 ;$ OF2 $=18.19 \pm 2.54, n=35$; CTRL $=18.17 \pm 4.79, n=$ 21). No differences in context fear were found between rats exposed to the open field 2-h before conditioning and control rats $\left(t_{54}=0.003, P=0.10,95 \%\right.$ CI $[-9.90,9.93], d<0.001$. Together, these results show the consistency of the performance of rats in each of the three conditions across experiments, and also that rats exposed to the open field $1 \mathrm{~h}$ before conditioning exhibit increased levels of context fear at test compared to either rats exposed to the open field 2-h before conditioning or to rats trained only, without any exposure to the open field (i.e., "CTRL"). This analysis also supports our claim that exposure to the open field 2-h before conditioning does not affect LTM formation as no differences were observed between rats exposed to the open field 2-h before and rats that were conditioned only (CTRL).

Early life experiences play an integral role in shaping later life development and functioning, highlighting the importance of understanding how memories are formed during this critical develop- mental period. While significant advances have been made in elucidating the neuro-molecular mechanisms underlying memory formation (see Johansen et al. 2011), much of this understanding has been derived from studies using adults. Infants, however, exhibit different behavioral outcomes following learning, suggesting that these findings in adults may not be readily translatable to the infant. For example, unlike adults, young animals exhibit spontaneous and rapid rates of forgetting, a phenomenon known as infantile amnesia (Campbell and Campbell 1962). Whether these differences in fear memory are, in part, due to the immature development of the neural structures and systems that support memory in the infant, or due to the use of a fundamentally different memory system remains controversial. The results of this study, however, appear to support the former position. Specifically, our results support the notion of a behavioral tagging process in infancy, suggesting that the impairments observed in context learning during infancy may be due to the limited availability or insufficient production of proteins. Whether the proteins that are captured during the behavioral tagging process are the same in infants and adults is unclear, as the fundamental proteins required for LTM memory formation in infants are unknown. Thus, basic experiments are needed in order to examine whether the proteins known to be critical for LTM in adults are also required in infants. These studies will assist in identifying candidate proteins that may be up-regulated and subsequently captured during the behavioral tagging process in the developing animal. Studies directly comparing behavioral tagging between infants and adults will also be useful in determining whether infants use similar, but perhaps less efficient mechanisms to encode a fear memory.

Overall, consistent with behavioral tagging principles and past work in adults, our results demonstrate that LTM formation in infant rats can be facilitated through brief exploration of an open field soon before learning. While these experiments were conceptualized and interpreted from the perspective of the behavioral tagging hypothesis (Moncada and Viola 2007), it must be acknowledged that arousal and/or stress could also be involved in the enhancement of the context fear memory observed in these experiments. That is, exposure to a large open field is likely to lead to some increase in arousal or stress. The effect of increased arousal/ stress on memory is complex (i.e., sometimes enhancing it, sometimes impairing it; for reviews, see de Quervain et al. 2017; Schwabe 2017). Although there is not a sizable literature on this issue, in a recent review Nomoto and Inokuchi (2018) suggested that "active spatial exploration, rather than stress, is a key element required to achieve hippocampus-dependent behavioral tagging in rodents" (p. 3). Nonetheless, future studies differentiating between these two potential underlying mechanisms will be important in order to elucidate the effect of open field exposure on LTM formation. Such studies may examine whether open field exposure also enhances memory for nonhippocampal tasks (e.g., cued conditioning). Given that behavioral tagging requires the colocalization of PRPs and tagged sites, open field exposure should not facilitate LTM for nonhippocampal tasks. If, however, the modulatory effect of open field exposure on LTM is due to arousal or stress, the modality of subsequent learning should not matter. Of note, while these modulatory factors (i.e., behavioral tagging versus arousal/ stress) may not be working through identical mechanisms, similar or interacting hormones and neurotransmitters are likely to be involved. For example, according to behavioral tagging principles, de novo protein synthesis induced by exposure to a novel open field is dependent on the activation of both dopamine $D_{1} / D_{5}$ and $\beta$-adrenergic receptors in the hippocampus (Moncada et al. 2011). These receptors also appear to have some role in modulating memory during periods of arousal and stress. For instance, there is considerable evidence showing that the primary stress hormone, glucocorticoid, enhances the consolidation of memories through 
interactions with adrenergic systems (Roozendaal et al. 1999, 2002). In addition, studies show that both glucose and epinephrine have wide-ranging effects on multiple neurotransmitters and receptors, including $\beta$-adrenergic receptors (see Homer et al. 1990; Gold 1995). Thus, while the specific mechanisms may differ, the primary molecules implicated in memory modulation across these different procedures appear to similarly promote memory, leading to the question of how these molecular dynamics may work in concert to promote a shift from short- to LTM. Understanding how memory modulators function and whether similar or interacting mechanisms are at play across paradigms may provide great theoretical insights into the processes involved in LTM in infancy.

Interestingly, contrary to behavioral tagging principles, familiarization did not abolish the facilitating effect of open field exposure on LTM formation in infant rats (Experiments 5 and 6). This stands in contrast to past studies in adult rats that reported familiarization of the open field abolished the behavioral tagging effect (Ballarini et al. 2009; Moncada et al. 2011). One possible explanation for this discrepancy is that infant rats may acquire, store, and/ or retrieve long-term representations for familiarization experiences differently compared to adult rats. Few studies have examined the neural mechanisms involved in the formation and retrieval of memories following familiarization and as such, future studies will be needed in order to explore this hypothesis at the mechanistic level. One study, however, has demonstrated that levels of pCREB were increased following exploration of a novel, but not familiar, environment in adult rats (Winograd and Viola 2004). Whether infant rats also exhibit this pattern of pCREB expression is unknown. Given our results showing that familiarization does not abolish the behavioral tagging effect in infant rats one could hypothesize that PCREB may remain increased following open field exposure in familiarized infant rats. Alternatively, pCREB may be qualitatively and/or quantitatively different in infancy compared to adulthood. An alternate explanation for this discrepancy is that the familiarization experience may act as an experiencedependent switch in hippocampal maturation. Recently, Alberini and Travaglia (2017) proposed that the hippocampus undergoes a developmental critical period paralleling those implicated in the development of the visual or auditory system (Huang et al. 1999; Berardi et al. 2000). This hypothesis was based on their study demonstrating that a single footshock at P24 led to good LTM, whereas at P17, it resulted in a latent memory trace that could be reactivated long after it had been forgotten (Travaglia et al. 2016). Similar to the mechanisms underlying the closure of developmental critical periods for sensory systems (Huang et al. 1999; Matta et al. 2011), the single shock training experience in infancy was associated with an mGluR5-mediated GluN2A/2B subunit switch in the hippocampus that peaked 24-h after learning. As such, it is possible that familiarizing infant rats to the open field resulted in an experience-dependent switch in GluN2A/2B subunit expression that accelerated the closure of the hippocampal critical period, promoting long-term contextual memories. This hypothesis will be investigated in future studies.

Over the past decade, emerging studies have demonstrated that behavioral tagging processes may underlie the formation of LTMs in adult rats. However, despite a large body of evidence demonstrating the importance of infantile experiences on later life development and brain function, no studies have examined such mechanisms in the developing animal. Understanding the processes involved in LTM in infancy may provide insight into how to prevent the negative effects of early adverse experiences on later life functioning. Our results suggest that a behavioral tagging mechanism paralleling that seen in adult rats may also underlie the formation of long-term contextual memories in infants. They further suggest that the mechanisms involved in
LTM formation following familiarization may be developmentally different.

\section{Materials and Methods}

\section{Subjects}

This study involved 245 experimentally naive Sprague-Dawley male rats (see Supplemental Methods). All animals were treated in accordance with the Australian Code of Practice for the Care and Use of Animals for Scientific Purposes (8th Edition, 2013), and all procedures were approved by the Animal Care and Ethics Committee at UNSW.

An open field arena and a set of MED Associates chambers were used (see the Supplemental Methods). In addition, a different conditioning chamber was used in Experiment 4 for administering the reinstatement shock (0.4 mA, 1-sec duration). During open field exposure, rats were placed in an open field for 5-min. During conditioning, following a 2-min adaptation period, six scrambled foot shocks (0.6 mA, 1-sec duration), separated by 30 -sec intervals, were delivered. Animals were tested back in the conditioned context for 3-min.

The behavior of the rats was scored as freezing or not freezing every $3 \mathrm{sec}$. Freezing was scored for any observation where there was the absence of all movement other than that required for respiration (Fanselow 1980). A random sample of $\sim 30 \%$ of the test data was cross-scored by an observer unaware of the experimental conditions. Inter-rater reliability was high for all experiments $(r=0.92-0.99)$. Freezing was analyzed by ANOVA and $t$-tests (Supplemental Methods).

\section{Acknowledgments}

We thank the funding bodies that supported this research: Australian Postgraduate Award (APA) to S.E.B. and a Discovery project grant from the Australian Research Council to R.R. (DP150104835).

\section{References}

Alberini CM, Travaglia A. 2017. Infantile amnesia: a critical period of learning to learn and remember. J Neurosci 37: 5783-5795.

Ballarini F, Moncada D, Martinez MC, Alen N, Viola H. 2009. Behavioral tagging is a general mechanism of long-term memory formation. Proc Natl Acad Sci 106: 14599-14604.

Bender RA, Lauterborn JC, Gall CM, Cariaga W, Baram TZ. 2001. Enhanced CREB phosphorylation in immature dentate gyrus granule cells precedes neurotrophin expression and indicates a specific role of CREB in granule cell differentiation. Eur J Neurosci 13: 679-686.

Berardi N, Pizzorusso T, Maffei L. 2000. Critical periods during sensory development. Curr Opin Neurobiol 10: 138-145.

Callaghan BL, Richardson R. 2011. Maternal separation results in early emergence of adult-like fear and extinction learning in infant rats. Behav Neurosci 125: 20-28.

Callaghan BL, Li S, Richardson R. 2014. The elusive engram: what can infantile amnesia tell us about memory? Trends Neurosci 37: 47-53.

Campbell BA, Campbell EH. 1962. Retention and extinction of learned fear in infant and adult rats. J Comp Physiol Psychol 55: 1-8.

Campbell BA, Spear NE. 1972. Ontogeny of memory. Psychol Rev 79: 215

de Carvalho Myskiw J, Benetti F, Izquierdo I. 2013. Behavioral tagging of extinction learning. Proc Natl Acad Sci 110: 1071-1076.

de Quervain D, Schwabe L, Roozendaal B. 2017. Stress, glucocorticoids and memory: implications for treating fear-related disorders. Nat Rev Neurosci 18: $7-19$.

Dunsmoor JE, Murty VP, Davachi L, Phelps EA. 2015. Emotional learning selectively and retroactively strengthens memories for related events. Nature 520: 345.

Fanselow MS. 1980. Signaled shock-free periods and preference for signaled shock. J Exp Psychol: Anim Behav Process 6: 65-80.

Frey U, Morris RG. 1997. Synaptic tagging and long-term potentiation. Nature 385: 533-536.

Gale GD, Anagnostaras SG, Godsil BP, Mitchell S, Nozawa T, Sage JR, Wiltgen W, Fanselow MS. 2004. Role of the basolateral amygdala in the storage of fear memories across the adult lifetime of rats. J Neurosci 24: 3810-3815. 
Gold PE. 1995. Role of glucose in regulating the brain and cognition. Am J Clin Nutr 61: 987-995.

Homer HC, Packan DR, Sapolsky RM. 1990. Glucocorticoids inhibit glucose transport in cultured hippocampal neurons and glia. Neuroendocrinology 52: $57-64$.

Huang ZJ, Kirkwood A, Pizzorusso T, Porciatti V, Morales B, Bear MF, Maffei L, Tonegawa S. 1999. BDNF regulates the maturation of inhibition and the critical period of plasticity in mouse visual cortex. Cell 98: 739-755.

Johansen JP, Cain CK, Ostroff LE, LeDoux JE. 2011. Molecular mechanisms of fear learning and memory. Cell 147: 509-524.

Josselyn SA, Frankland PW. 2012. Infantile amnesia: a neurogenic hypothesis. Learn Mem 19: 423-433.

Kabitzke PA, Silva L, Wiedenmayer C. 2011. Norepinephrine mediates contextual fear learning and hippocampal pCREB in juvenile rats exposed to predator odor. Neurobiol Learn Mem 96: 166-172.

Li S, Callaghan BL, Richardson R. 2014. Infantile amnesia: forgotten but not gone. Learn Mem 21: 135-139.

Madsen HB, Kim JH. 2016. Ontogeny of memory: an update on 40 years of work on infantile amnesia. Behav Brain Res 298: 4-14.

Matta JA, Ashby MC, Sanz-Clemente A, Roche KW, Isaac JT. 2011. mGluR5 and NMDA receptors drive the experience- and activity-dependent NMDA receptor NR2B to NR2A subunit switch. Neuron 70: 339-351.

Moncada D, Viola H. 2006. Phosphorylation state of CREB in the rat hippocampus: a molecular switch between spatial novelty and spatial familiarity? Neurobiol Learn Mem 86: 9-18.

Moncada D, Viola H. 2007. Induction of long-term memory by exposure to novelty requires protein synthesis: evidence for a behavioral tagging. J Neurosci 27: 7476-7481.

Moncada D, Ballarini F, Martinez MC, Frey JU, Viola H. 2011. Identification of transmitter systems and learning tag molecules involved in behavioral tagging during memory formation. Proc Natl Acad Sci 108: 12931-12936.

Nomoto M, Inokuchi K. 2018. Behavioral, cellular, and synaptic tagging frameworks. Neurobiol Learn Mem 153: 13-20.
Roozendaal B, Nguyen BT, Power AE, McGaugh JL. 1999. Basolateral amygdala noradrenergic influence enables enhancement of memory consolidation induced by hippocampal glucocorticoid receptor activation. Proc Natl Acad Sci 96: 11642-11647.

Roozendaal B, Quirarte GL, McGaugh JL. 2002. Glucocorticoids interact with the basolateral amygdala $\beta$-adrenoceptor-cAMP/cAMP/PKA system in influencing memory consolidation. Euro J Neurosci 15: 553-560.

Rudy JW. 1993. Contextual conditioning and auditory cue conditioning dissociate during development. Behav Neurosci 107: 887.

Rudy JW, Morledge P. 1994. Ontogeny of contextual fear conditioning in rats: implications for consolidation, infantile amnesia, and hippocampal system function. Behav Neurosci 108: 227.

Schwabe L. 2017. Memory under stress: from single systems to network changes. Euro J Neurosci 45: 478-489.

Spear NE, Parsons PJ. 1976. Analysis of a reactivation treatment: ontogenetic determinants of alleviated forgetting. In Coding processes in animal memory (ed. Medin D, et al.), pp. 135-165. Erlbaum, Hillsdale, NJ.

Travaglia A, Bisaz R, Sweet ES, Blitzer RD, Alberini CM. 2016. Infantile amnesia reflects a developmental critical period for hippocampal learning. Nat Neurosci 19: 1225.

Weber M, McNally GP, Richardson R. 2006. Opioid receptors regulate retrieval of infant fear memories: effects of naloxone on infantile amnesia. Behav Neurosci 120: 702.

Winograd M, Viola H. 2004. Detection of novelty, but not memory of spatial habituation, is associated with an increase in phosphorylated cAMP response element-binding protein levels in the hippocampus. Hippocampus 14: 117-123.

Woodcock EA, Richardson R. 2000. Effects of multisensory environmental stimulation on contextual conditioning in the developing rat. Neurobiol Learn Mem 74: 89-104.

Received March 22, 2018; accepted in revised form August 28, 2018. 


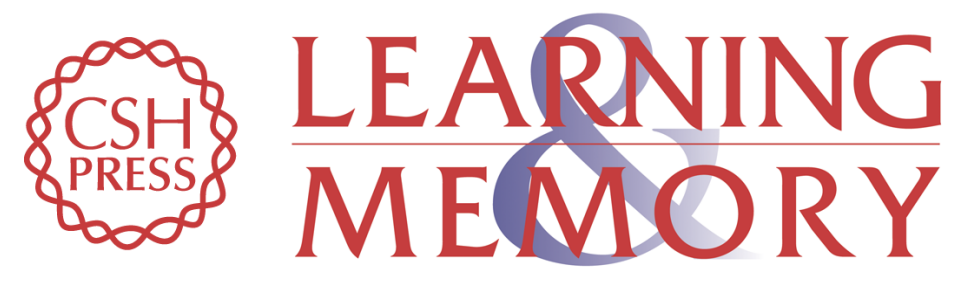

\section{Behavioral tagging in infant rats}

Sarah E. Bae and Rick Richardson

Learn. Mem. 2018, 25:

Access the most recent version at doi:10.1101//m.047605.118

Supplemental http://learnmem.cshlp.org/content/suppl/2018/10/09/25.11.580.DC1

References This article cites 36 articles, 9 of which can be accessed free at: http://learnmem.cshlp.org/content/25/11/580.full.html\#ref-list-1

Creative This article is distributed exclusively by Cold Spring Harbor Laboratory Press for the Commons first 12 months after the full-issue publication date (see

License http://learnmem.cshlp.org/site/misc/terms.xhtml). After 12 months, it is available under a Creative Commons License (Attribution-NonCommercial 4.0 International), as described at http://creativecommons.org/licenses/by-nc/4.0/.

Email Alerting Receive free email alerts when new articles cite this article - sign up in the box at the Service top right corner of the article or click here. 